\title{
Editorial
}

\section{Late Psychosocial Consequences of Pandemics, from HIV to Covid}

CSWHI 2021; 12(2): 6 - 7; DOI: 10.22359/cswhi_12_2_15 C C Clinical Social Work and Health Intervention

Following Issue of Clinical Social work number 2.2021 appears just after one year after the onset of one of the worst pandemics within the last 40 years worldwide.

If we remember the onset of HIV epidemics originating in America and Africa, spreading worldwide in 1980, and now 2020 Covid pandemics, within those four decades several alert have been given by WHO but sometimes ignored by EU and North America, also because effective HIV treatments has been introduced in 1999 ,bringing the numbers after 2010 definitely down and decreasing mortality in those infected from 100 to 1 percent. Also mother to child transmission of HIV decreased from 20 to 1 percent within last 25 years.(1.2)

Unfortunately, winning the battle (but not was) with HIV bought the community to lethargy worldwide, ignoring other alerts which fortunately were not major killers as HIV TB and malaria, but were predictors for the uncontrolled streads, specially when air transport has been increased from 1980 to 2020 more than 10 times, enabling to bring the disease rapidly via all continents. So called ,small, epidemics such as SARS in 2002, Avian influenza in 1995, other zoonotic flu (swine origin) 2010, MERS 2014, Zika 2016, Ebola 2015, Yellow fever 2018, all those were transmitted by air travel but fortunately rapid cessation of air travel, draconic isolation and quarantine in focuses helped us not only to stop the epidemics early, but gave us impression that WHO and health care systems can prevent everything, protect everybody, and the scientific community has vaccines for all infectious diseases.

However last years showed us that this is not true and control of last 10 epidemics ameliorated completely our vigilance. The results is up to 4 million deaths and 300 
million infected, despite of fabulous success of vaccination development. Due to vaccines and quarantines, the second wawe as well as the first part of third epidemics is currently promising us better summer, however new variants must keep the health authorities awake. Deaths and collapse of economics is an immediate visible relict (we hope) of this pandemic. This issue of CSW keeps our eyes more open in the late consequences: social and psychic trauma, including protcovid syndromes, related pandemics such as epidemy of depression, obesity, addictions, pharmacy and health care workers burnout syndromes, devastating effect due to isolation of elderly and mental health facilities etc. Despite we can predict many times first or second wawes of infectious diseases and deaths, or economy quakes ,we are afraid that we still cannot predict the psychosocial consequences of all those small (Ebola, MERS, SARS) or large epidemics such as HIV and Covid, which may take us decades.

\section{Radi Francis}

Bundzelova Katarina

Bl Max Kolbe House of Hope Phnompenh SEU Social work Trop programme, Kingdom of Cambodia

Olah Michal

Muss Claus

IGAP Vienna Austria and SEU Training Ctr Zurich Switzerland

\section{Contact address:}

e-mail: mussprof@yahoo.fr

\section{References:}

1. WHO Annual Report. 2018. Geneva, WHO. wwww.aho.org

2. United Nations AIDS office. UN New York. www.unaids.org 